\title{
Penerapan dan pendampingan pengelolaan website sekolah di SMP Negeri 4 Jombang
}

\author{
Kartikadyota Kusumaningtyas ${ }^{*}$, Eko Dwi Nugroho, Adri Priadana \\ Program Studi Informatika, Fakultas Teknik dan Teknologi Informasi \\ Universitas Jenderal Achmad Yani Yogyakarta \\ Email Korespondensi: "kartikadyota@gmail.com
}

Received December 12, 2020; Revised February 25, 2021; Accepted March 11, 2021

\begin{abstract}
Abstrak
Internet telah menjadi salah satu media untuk tujuan pemasaran. Salah satu upaya dalam pemanfaatan media internet adalah untuk proses identitas merek atau sering disebut branding digital. Branding digital juga menjadi salah satu cara untuk menjaga eksistensi suatu lembaga pendidikan. SMP Negeri 4 Jombang merupakan salah satu sekolah tingkat menengah pertama yang terletak di Kabupaten Jombang, Jawa Timur. Permasalahan utama yang dihadapi oleh SMP Negeri 4 Jombang adalah terkait promosi melalui media digital yang belum maksimal dan banyaknya informasi yang ingin disampaikan, baik kepada siswa, orang tua, alumni, maupun kepada masyarakat masih belum dapat disampaikan secara maksimal. Mengarah pada permasalahanpermasalahan tersebut, maka diperlukan adanya sebuah website sekolah. Selain itu, diperlukan juga pendampingan pengelolaan website sekolah agar pihak sekolah dapat mengelola website-nya dengan optimal, baik dalam mengisikan konten profil sekolah, maupun dalam mengisikan konten kegiatan atau berita terkait SMP Negeri 4 Jombang. Tahapan pelaksanaan kegiatan ini terdiri dari tiga tahap, yaitu identifikasi masalah, instalasi web sekolah., serta pelatihan dan pendampingan. Hasil dari kegiatan ini adalah peserta dapat melakukan pengelolaan website sekolah dengan baik. Selain itu, dengan adanya website sekolah, maka dapat membantu promosi SMP Negeri 4 Jombang dan juga sebagai sarana penyampaian informasi ke siswa, orang tua, alumni, maupun kepada masyarakat luas.
\end{abstract}

Kata Kunci: branding digital; website sekolah; pengelolaan web

\begin{abstract}
The internet has become a medium for marketing purposes. One of the efforts to utilize internet media is to process brand identity or often called digital branding. Digital branding is also one way to maintain the existence of an educational institution. SMP Negeri 4 Jombang is one of the junior high schools located in Jombang Regency, East Java. The main problem faced by SMP Negeri 4 Jombang is related to promotion through digital media that has not been maximized. The amount of information conveyed to students, parents, alumni, and the community cannot be given optimally. Towards these problems, it is necessary to have a school website. Besides, assistance in managing the school website is also needed to operate its website optimally, filling in school profile content, and filling in activity content or news related to SMP Negeri 4 Jombang. This activity consists of three stages. Those are problem identification, school web installation, as well as training and mentoring. The result of this activity is that participants can manage the school website well. The school website can also promote SMP Negeri 4 Jombang and as a means of delivering information to students, parents, alumni, and the wider community.
\end{abstract}

Keywords : digital branding; school website; web management

\section{PENDAHULUAN}

Berkembangnya teknologi saat ini telah membuat pengguna internet semakin meningkat, khususnya untuk memenuhi kebutuhan di era digital ini. Hampir semua layanan yang ada saat ini dapat diakses melalui internet. Dalam bidang pendidikan, bayak layanan yang memanfaatkan teknologi dan internet untuk mendukung poroses belajar mengajar. Afriansyah dan Pratama di tahun 2020 [1] mengimplementasi sistem ujian berbasis komputer di SMP Negeri 1 Sungailiat dimana sistem tersebut dapat diakses melalui internet. Bahar dkk di tahun 2020 [2] memanfaatkan media pembelajaran online bernama Kahoot yang digunakan untuk memdukung proses pembelajaran interaktif dimaan media tersebut dapat diakses melalui internet. Selain itu, internet telah menjadi salah satu media untuk tujuan pemasaran. Salah satu upaya dalam pemanfaatan media internet adalah untuk proses identitas merek atau sering disebut branding digital. Tidak hanya bagi 
perusahaan atau produk, branding digital juga menjadi sangatlah penting bagi lembaga pendidikan [3]. Selain itu, branding digital juga menjadi salah satu cara untuk menjaga eksistensi suatu lembaga pendidikan. Eksistensi suatu lembaga pendidikan seperti sekolah sangatlah penting khususnya untuk mendapatkan banyak peserta didik baru setiap tahunnya. Selain itu, lembaga pendidikan perlu memiliki branding yang mapan untuk menyikapi ketatnya persaingan dalam penerimaan peserta didik baru. Hal ini karena mayoritas masyarakat mengambil keputusan dalam memilih lembaga pendidikan dengan memandang branding yang di miliki lembaga pendidikan tersebut [4].

Dalam melakukan branding digital, sekolah dapat menempuh banyak cara. Selain memanfaatkan media sosial seperti yang dijelaskan pada penelitian yang dilakukan oleh Pernama dkk di tahun 2020 [5], branding digital juga dapat dilakukan melalui website sekolah. Adanya website sekolah akan membuat masyarakat dapat dengan mudah mencari tau terkait profil dari sekolah tersebut. Adanya website sekolah, pihak sekolah juga dapat memberikan konten yang positif bagi publik seperti menghadirkan informasi kegiatan sekolah sehingga masyarakat dapat mengetahuinya [6]. Hal ini juga dapat menumbuhkan kepercayaan masyarakat kepada sekolah. Selain itu, website sekolah telah terbukti dapat menjadi alat promosi yang lebih baik daripada poster dan flier [7].

SMP Negeri 4 Jombang merupakan sebuah sekolah tingkat menengah pertama yang terletak di Kabupaten Jombang Provinsi Jawa Timur. SMP Negeri 4 Jombang telah berdiri sejak tanggal 22 November 1985 dimana memiliki visi "berprestasi dalam IPTEK berlandaskan IMTAQ, berbudaya luhur serta perduli lingkungan”. SMP Negeri 4 Jombang terus berupaya untuk dapat mewujudkan sekolah yang berprestasi dan menghasilkan lulusan yang berakhlaqul karimah.

Berdasarkan wawancara yang dilakukan kepada Kepala Sekolah SMP Negeri 4 Jombang, Bapak Rudy Yoso Adinugroho, S.Pd., M.Si. pada bulan Agustus 2020, terdapat beberapa permasalahan di SMP Negeri 4 Jombang. Permasalahan utama yang dihadapi adalah terkait promosi SMP Negeri 4 Jombang melalui media digital masih belum maksimal. Permasalahan lain adalah banyaknya informasi terkait SMP Negeri 4 Jombang yang ingin disampaikan, baik kepada siswa, orang tua, alumni, maupun kepada masyarakat masih belum dapat disampaikan secara maksimal.

Mengarah pada permasalahan-permasalahan tersebut, maka diperlukan adanya sebuah website sekolah di SMP Negeri 4 Jombang. Selain itu, diperlukan juga pendampingan pengelolaan website sekolah agar pihak sekolah dapat mengelola website-nya dengan optimal, baik dalam mengisikan konten profil sekolah, maupun dalam mengisikan konten kegiatan atau berita terkait SMP Negeri 4 Jombang. Oleh karena itu dalam kegiatan Pengabdian pada Masyarakat Semester Gasal tahun ajaran 2020/2021 ini, kami melakukan kegiatan penerapan dan pendampingan pengelolaan website sekolah di SMP Negeri 4 Jombang.

Dalam membangun atau menerapkan sebuah website diperlukan sebuah web hosting dan domain [8]. Web hosting merupakan salah satu bentuk layanan jasa penyewaan tempat di Internet yang memungkinkan pemangku kepentingan dapat menampilkan layanannya pada sebuah web / situs dan dapat diakses melalui internet [9]. Domain merupakan sebuah identifikasi alamat website untuk mengganti nama dari alamat IP menjadi kata-kata sehingga dapat dengan mudah untuk diingat dan dihafal [10]. Dalam kegiatan Pengabdian kepada Masyarakat ini, kami bekerjasama dengan pihak PT. Citraweb Digital Multisolusi dalam penerapan website sekolah baik dari segi produk website sekolah, maupun dari segi web hosting beserta domain-nya. PT. Citraweb Digital Multisolusi adalah perusahaan teknologi informasi berdiri sejak tahun 2000 di Yogyakarta.

\section{METODE}

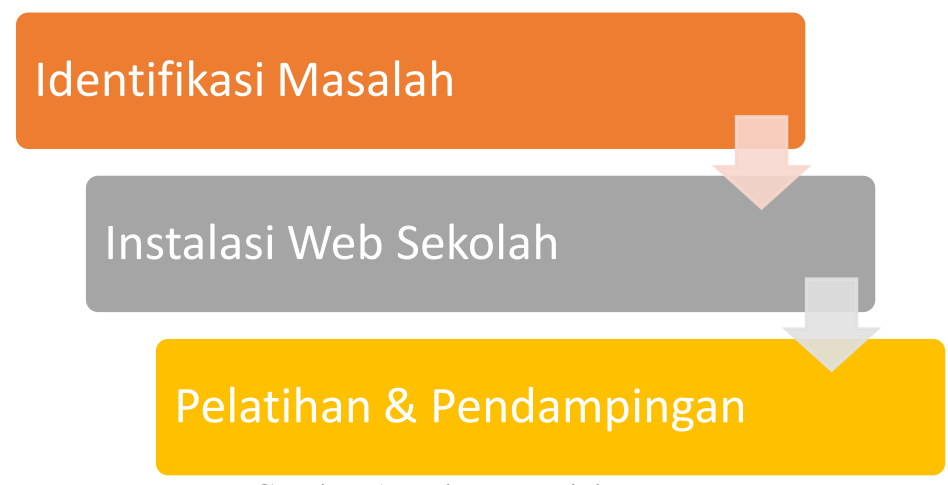

Gambar 1. Tahapan pelaksanaan 
Tahapan pelaksanaan kegiatan penerapan dan pendampingan pengelolaan website sekolah di SMP Negeri 4 Jombang ini terdiri dari tiga tahap (ditunjukkan pada Gambar 1), yaitu: (1) Identifikasi masalah, (2) Instalasi web sekolah., dan (3) Pelatihan dan pendampingan.

1) Identifikasi Masalah

Tahap identifikasi masalah dilakukan untuk mengetahui permasalahan yang terjadi di SMP Negeri 4 Jombang. Metode yang digunakan adalah survei dan wawancara. Selanjutnya, hasil survei dan wawancara dipetakan dalam bentuk analisis SWOT.

Analisis SWOT merupakan bentuk analisis situasi dan kondisi yang bersifat deskriptif yang ditujukan untuk menggambarkan situasi yang sedang dihadapi atau mungkin akan dihadapi oleh organisasi. Analisis ini didasarkan agar dapat memaksimalkan kekuatan (strengths) dan peluang (opportunities), yang secara bersamaan dapat meminimalkan kelemahan (weaknesses) dan ancaman (threats)[11]. Tabel 1 menunjukkan hasil analisis SWOT di SMP Negeri 4 Jombang.

Tabel 1. Analisis SWOT

\begin{tabular}{|c|c|}
\hline STRENGTHS (S) & WEAKNESSES $(W)$ \\
\hline o Sekolah telah memiliki infrastruktur yang & o Keterbatasan penggunaan media informasi \\
\hline memadai & o Belum memiliki website sekolah \\
\hline o Sekolah memiliki staf IT & o Keterbatasan kemampuan staf IT dalam \\
\hline o Sekolah memiliki banyak prestasi & mengelola website sekolah \\
\hline o Sekolah memiliki 24 rombongan belajar & \\
\hline OPPORTUNITY $(O)$ & THREATS $(T)$ \\
\hline $\begin{array}{l}\text { O Kemajuan teknologi di Kabupaten Jombang } \\
\text { sudah mendukung }\end{array}$ & o Persaingan branding antar sekolah \\
\hline o Tersedianya koneksi internet yang memadai & \\
\hline $\begin{array}{l}\text { - Masyarakat telah memanfaatkan internet untuk } \\
\text { pencarian informasi }\end{array}$ & \\
\hline
\end{tabular}

2) Instalasi Web Sekolah

PT. Citraweb Digital Multisolusi menyediakan produk website sekolah, hosting, dan domain, serta bertanggung jawab untuk melakukan instalasi. Untuk keperluan domain, pihak sekolah mengajukan nama domain yang diinginkan melalui surat permohonan nama domain.

3) Pelatihan dan Pendampingan

Kegiatan pada tahap ini dibagi menjadi 2 sesi, yaitu:

a. Sesi Pelatihan

Tim dari Universitas Jenderal Achmad Yani Yogyakarta memberikan pelatihan terkait pengelolaan website sekolah. Materi yang disampaikan meliputi pengenalan halaman front-end dan halaman backend, identifikasi kebutuhan konten, dan pengelolaan konten, seperti post, page, agenda, album, testimonial, hubungi kami, welcome, speciality, dan slider. Sesi pelatihan dilaksanakan sebanyak 2 kali pertemuan dengan durasi tiap pertemuan adalah 4 jam. Metode yang digunakan pada kegiatan pelatihan adalah metode tutorial dimana pembicara menyampaikan materi terlebih dahulu kemudian peserta mengikuti dengan melakukan praktik.

b. Sesi Pendampingan

Ketika sesi pendampingan, tim Universitas Jenderal Achmad Yani Yogyakarta berperan sebagai mentor. Mentor akan mengawasi dan memberikan saran terkait pengelolaan website sekolah yang dilakukan oleh peserta. Kegiatan pendampingan berlangsung selama tiga bulan dimana di setiap bulan mentor akan melakukan monitoring terhadap progress peserta dalam melakukan pengelolaan website sekolah. Metode yang digunakan pada kegiatan ini adalah diskusi.

\section{HASIL DAN PEMBAHASAN}

Kegiatan penerapan dan pendampingan pengelolaan website dilaksanakan pada tanggal 24 Agustus 2020 hingga 27 November 2020. Sasaran kegiatan ini adalah Bapak/Ibu Guru dan Staf SMP Negeri 4 Jombang yang ditunjuk sebagai penanggung jawab website sekolah. Hasil dari kegiatan ini adalah sebagai berikut.

1) Identifikasi Masalah

Langkah awal yang dilakukan untuk mengidentifikasi permasalahan adalah dengan melakukan survei. Survei ini berisi pertanyaan-pertanyaan dasar terkait keadaan sekolah. Selanjutnya hasil survei akan dibahas lebih detail melalui wawancara dengan Kepala Sekolah SMP Negeri 4 Jombang, Bapak Rudy Yoso Adinugroho, S.Pd., M.Si. (ditunjukkan pada Gambar 2). 


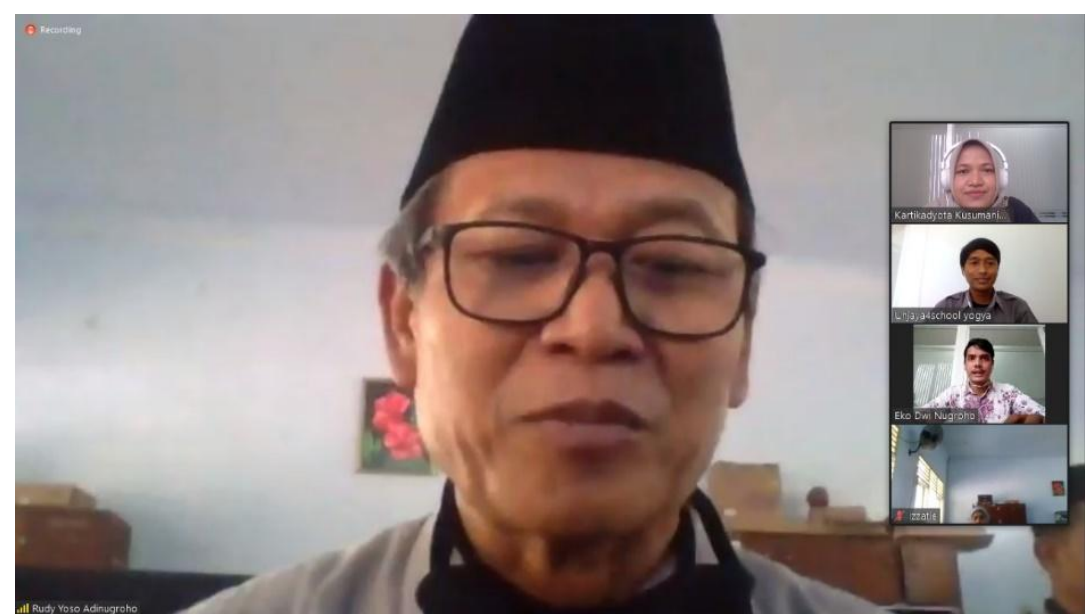

Gambar 2. Wawancara dengan Kepala Sekolah SMP Negeri 4 Jombang

Hasil wawancara yang dilaksanakan pada pertengahan bulan Agustus 2020 adalah adanya permasalahan utama yang dihadapi sekolah terkait promosi melalui media digital dan banyaknya informasi terkait SMP Negeri 4 Jombang yang ingin disampaikan, baik kepada siswa, orang tua, alumni, maupun kepada masyarakat yang masih belum maksimal.

Berdasarkan uraian permasalahan tersebut, maka diperlukan adanya website sekolah di SMP Negeri 4 Jombang. Agar dapat mengelola website sekolah dengan optimal, maka perlu diadakan kegiatan pendampingan pengelolaan website sekolah. Adapun penanggung jawab website sekolah yang telah ditunjuk dapat dilihat pada Tabel 2.

Tabel 2. Penanggung jawab website sekolah di SMP Negeri 4 Jombang

\begin{tabular}{cll}
\hline No. & \multicolumn{1}{c}{ Jabatan } & Jumlah \\
\hline 1. & Kepala Sekolah & 1 orang \\
2. & Humas & 2 orang \\
3. & Guru IT & 2 orang \\
4. & Staf perpustakaan & 2 orang \\
5. & Staf tata usaha & 4 orang \\
\hline
\end{tabular}

2) Instalasi Web Sekolah

Setelah pihak sekolah mengajukan surat permohonan nama domain, selanjutnya PT. Citraweb Digital Multisolusi melakukan instalasi website sekolah sesuai dengan domain yang diajukan, yakni https://smpnegeri4jombang.sch.id.

3) Pelatihan dan Pendampingan

a. Sesi Pelatihan

Sesi pelatihan dilaksanakan sebanyak 2 kali pertemuan tatap muka virtual melalui Zoom yaitu pada tanggal 24 Agustus 2020 dan 27 Agustus 2020. Kegiatan pelatihan hari pertama diawali dengan pembukaan oleh ketua tim Universitas Jenderal Achmad Yani Yogyakarta. Selanjutnya ketua tim membagikan link presensi kepada peserta melalui kolom chat Zoom.

Materi yang disampaikan pada pertemuan pertama adalah pengenalan halaman front-end (ditunjukkan Gambar 3) dan halaman back-end serta identifikasi kebutuhan konten yang harus disiapkan. Suasana pelatihan pada hari pertama dapat dilihat pada Gambar 4. 


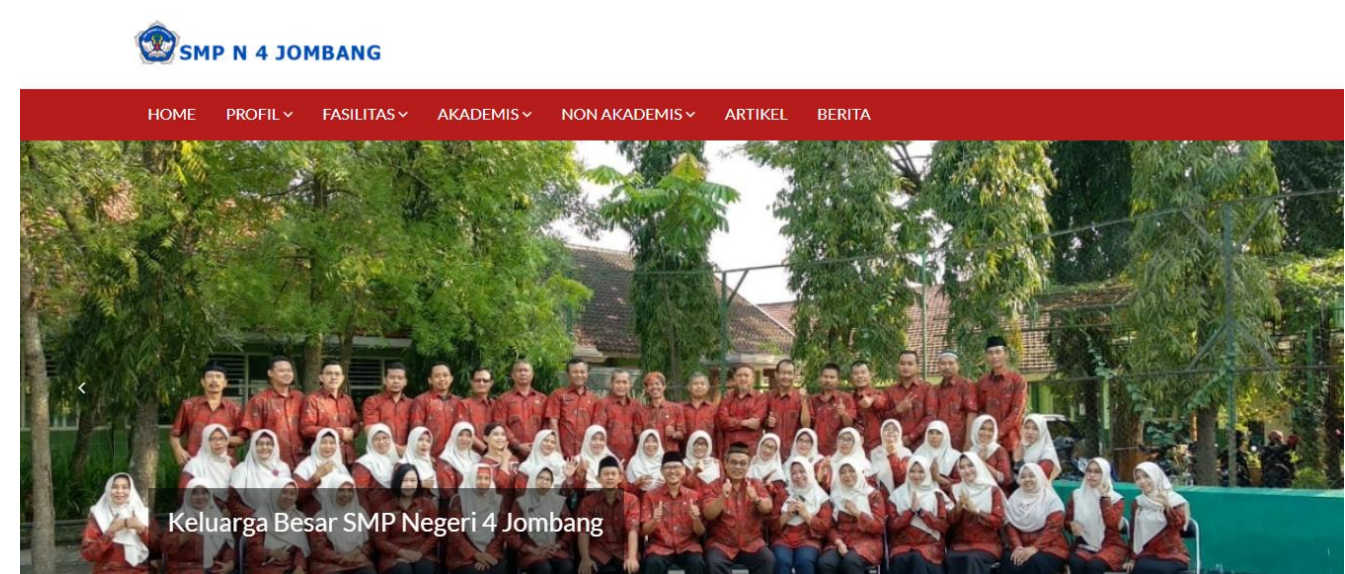

Gambar 3. Halaman front-end website
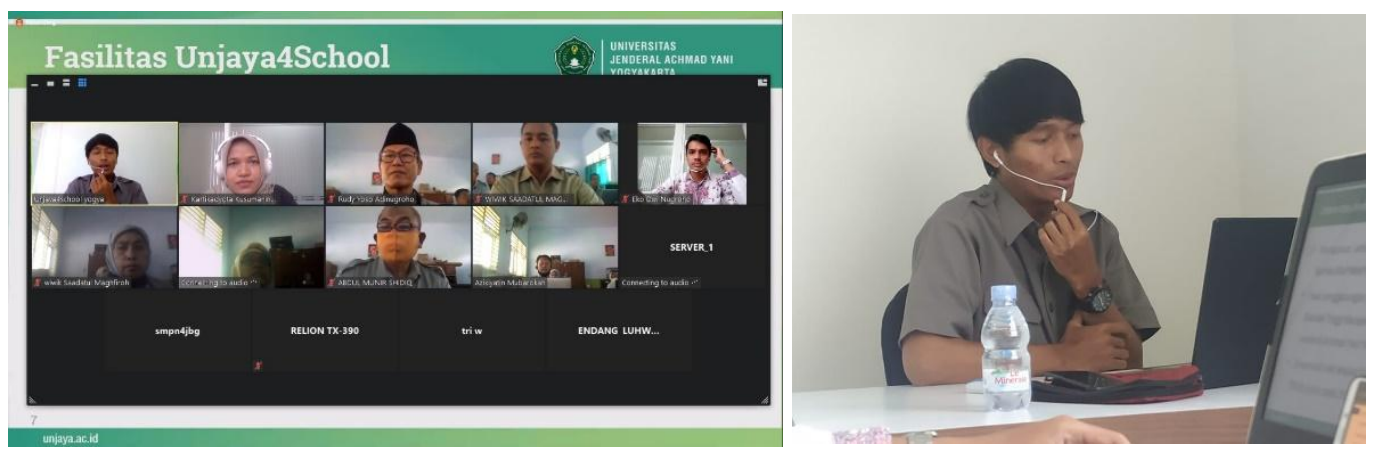

Gambar 4. Suasana pelatihan hari pertama

Pelatihan hari kedua diawali dengan membagikan link presensi kepada peserta kemudian dilanjutkan dengan materi terkait pengelolaan website, meliputi: Posts, Pages, Agenda, Album, Testimonial, Hubungi Kami, Welcome, Speciality, dan Slider. Suasana pelatihan pada hari kedua dapat dilihat pada Gambar 5.

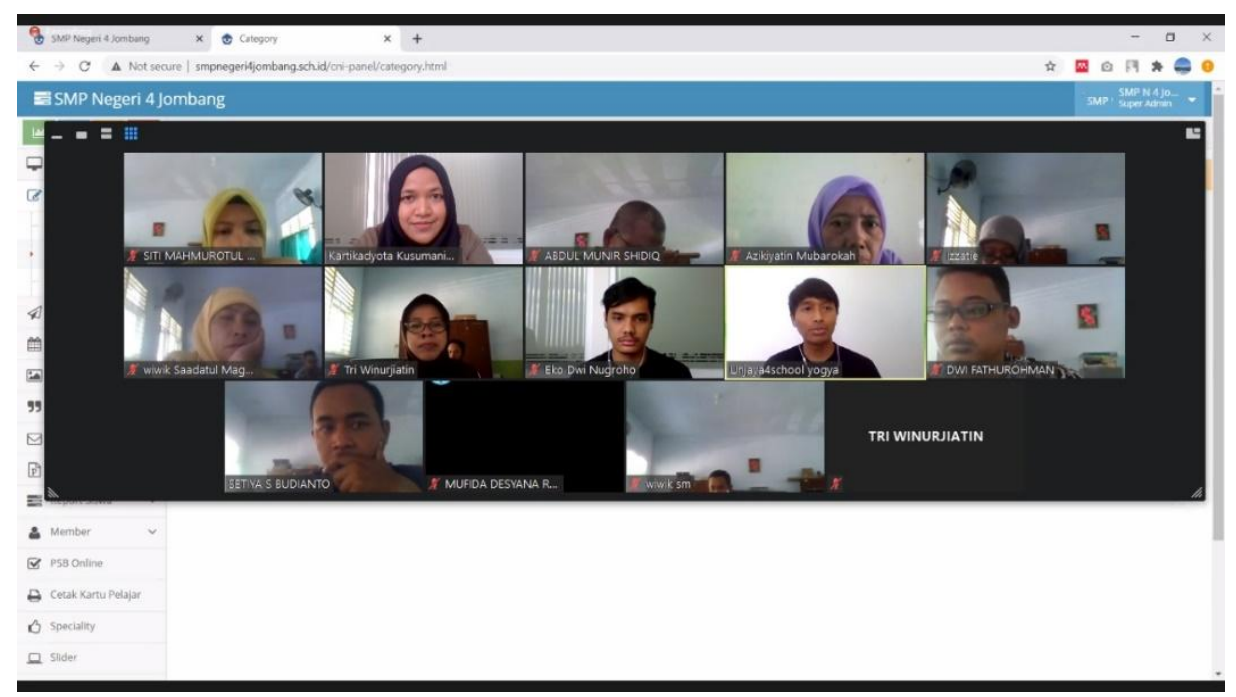

Gambar 5. Suasana pelatihan hari kedua

Penyampaian materi dilakukan dengan metode tutorial dimana pembicara menjelaskan langkahlangkahnya kemudian peserta mengikutinya dengan praktik. Hasil pelatihan hari kedua adalah peserta 
dapat melakukan pengelolaan website. Sebagai contoh, peserta dapat melakukan pengelolaan halaman Tentang Kami (ditunjukkan Gambar 6).

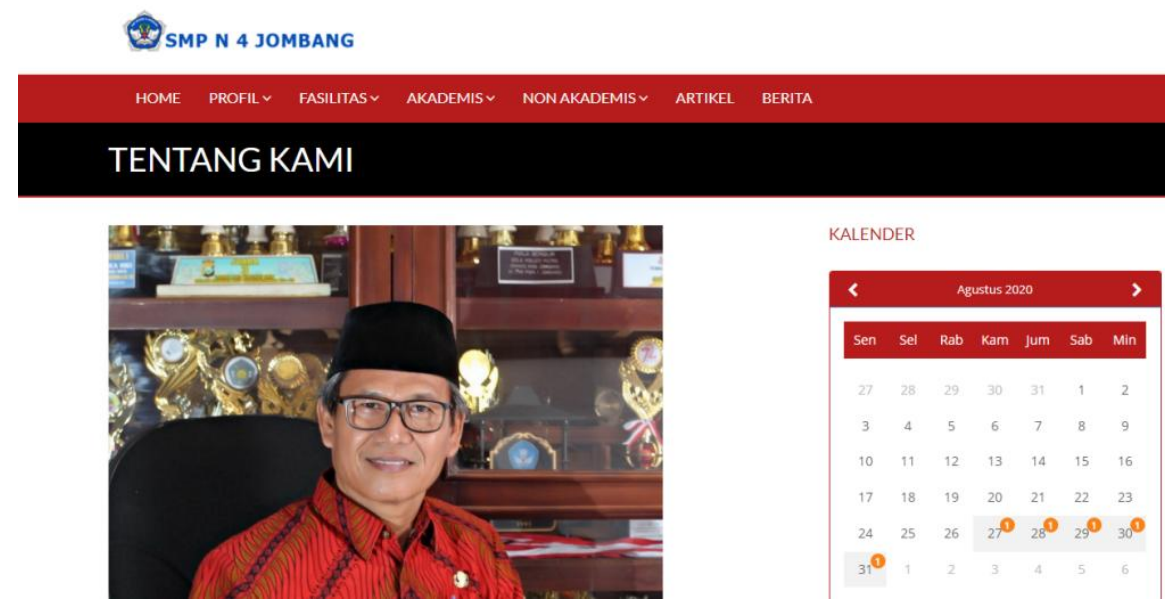

Gambar 6. Hasil pengelolaan halaman Tentang Kami

Peserta juga telah dapat menambahkan gambar pada Slider, mengubah gambar Slider, dan juga mengubah konten Welcome (ditunjukkan Gambar 7). Selain itu peserta juga telah dapat mengelola konten Agenda (ditunjukkan Gambar 8).

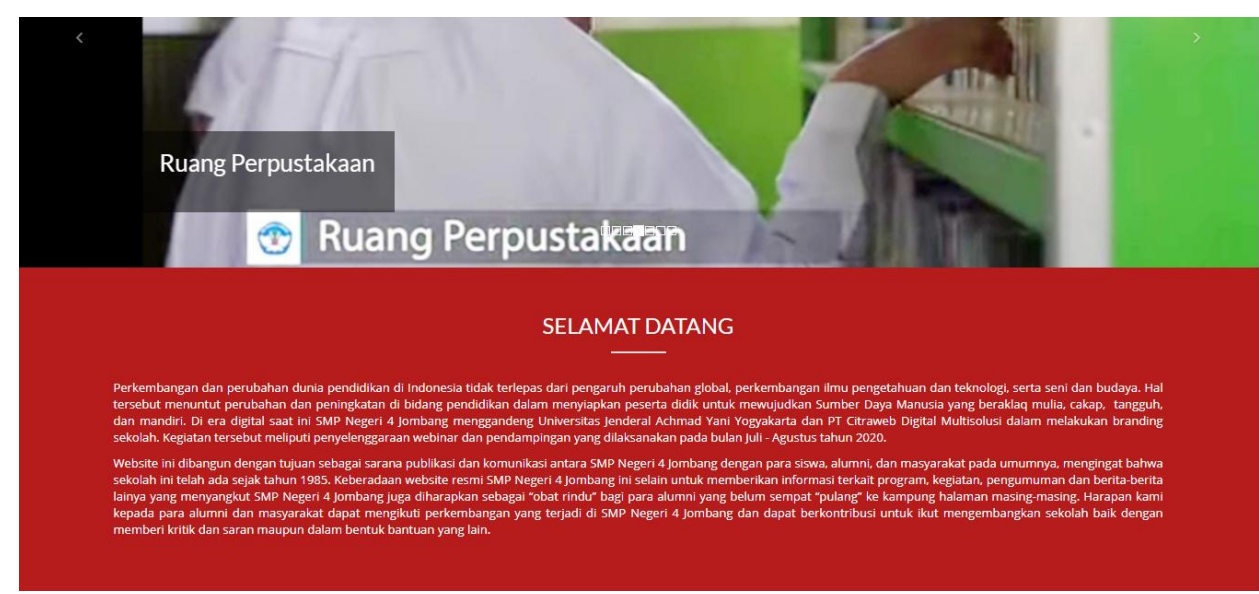

Gambar 7. Hasil pengelolaan konten Slider dan Welcome

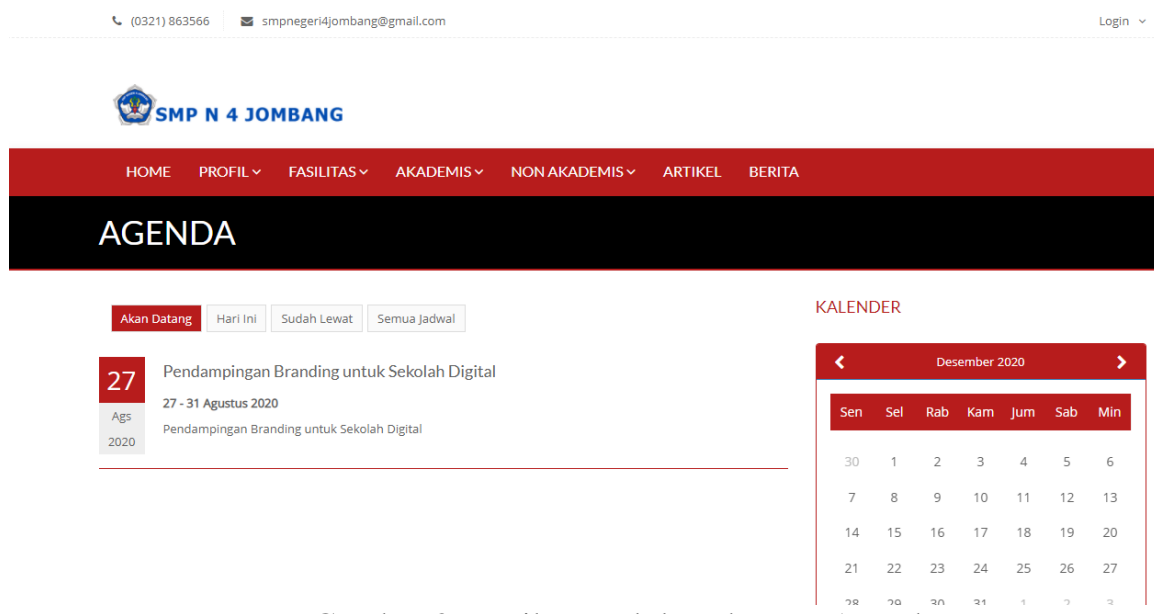

Gambar 8. Hasil pengelolaan konten Agenda 
b. Sesi Pendampingan

Kegiatan pendampingan berlangsung selama tiga bulan dimana di setiap bulan tim Universitas Jenderal Achmad Yani Yogyakrta melakukan monitoring terhadap progress peserta dalam melakukan pengelolaan website sekolah melalui Grup Whatsapp. Untuk kelancaran peserta dalam melakukan pengelolaan website sekolah, tim Universitas Jenderal Achmad Yani Yogyakarta telah merangkum isi materi pada sesi pelatihan ke dalam sebuah modul pengelolaan website sekolah. Modul tersebut dapat digunakan sebagai panduan peserta dalam melakukan pengelolaan website sekolah.

Pada bulan pertama pendampingan, peserta menambahkan Agenda untuk kegiatan Penilaian Tengah Semester 1 (ditunjukkan Gambar 9). Selain itu peserta juga melengkapi konten yang lain, seperti Album, Video, dan juga halaman Sejarah.

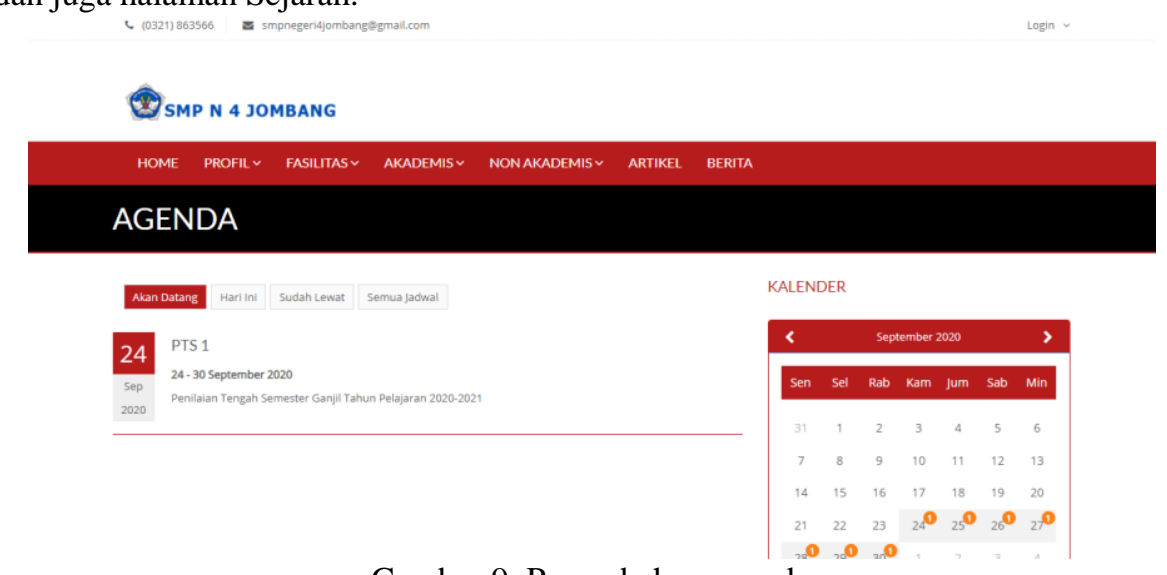

Gambar 9. Penambahan agenda

Selanjutnya pada bulan kedua dan ketiga peserta telah menambahkan beberapa video pada Album Video (ditunjukkan Gambar 10). Selain itu peserta juga menambahkan beberapa tulisan pada kolom berita. Salah satu cuplikan tulisan yang telah terbit ditunjukkan Gambar 11.
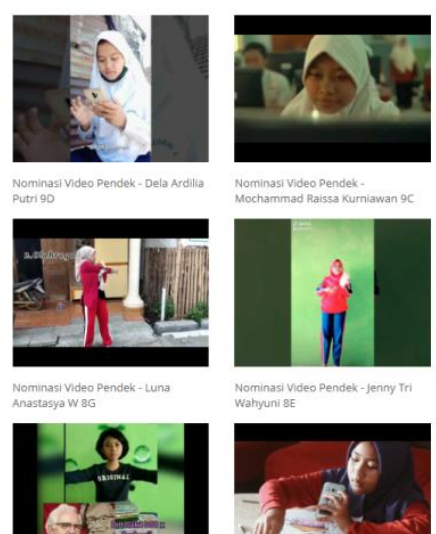

Gambar 10. Menambahkan video pada Album Video
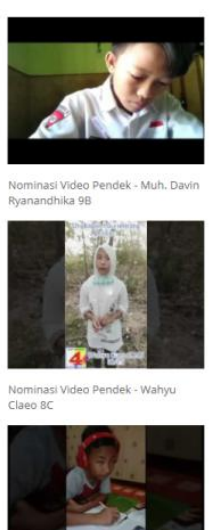

BERITATERKINI

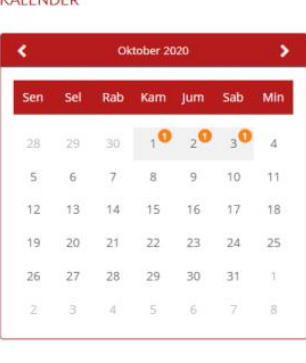

pemenang lomba video pendek sima

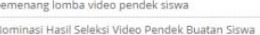

Pendek Buatan Siswa 


\section{BERITA}

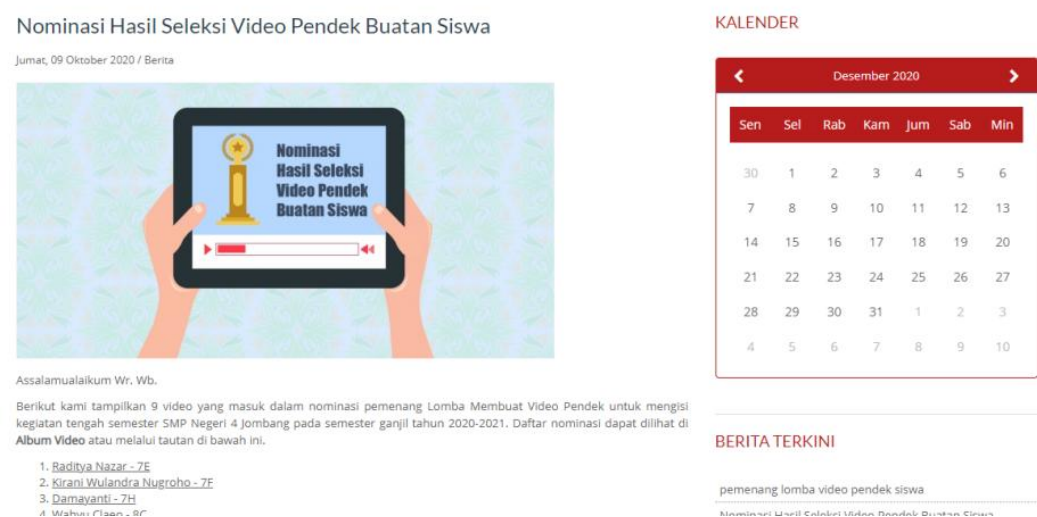

Gambar 11. Penambahan tulisan di kolom Berita

Berdasarkan pengamatan saat sesi pendampingan, terdapat banyak peningkatan kemampuan peserta dalam memanfaatkan website sekolah dan melakukan pengelolaan website sekolah. Pada Gambar 11 dapat dilihat bahwa peserta telah dapat membuat tulisan secara mandiri yang memanfaatkan tautan (link). Dengan adanya website sekolah yang dapat dikelola dengan baik, maka dapat memajukan sekolah khususnya dalam penyebaran informasi yang sejalan dengan kemajuan teknologi masyarakat Kabupaten Jombang.

\section{KESIMPULAN}

Berdasarkan pelaksanaan kegiatan Penerapan dan Pendampingan Pengelolaan Website Sekolah di SMP Negeri 4 Jombang dapat diperoleh kesimpulan bahwa peserta yang ditugaskan sebagai penanggung jawab website sekolah telah dapat melakukan pengelolaan website sekolah dengan baik. Adanya website sekolah juga dapat membantu promosi SMP Negeri 4 Jombang dan juga sebagai sarana penyampaian informasi ke siswa, orang tua, alumni, maupun kepada masyarakat luas. Kegiatan ini berjalan dengan baik dan mendapatkan respon positif dari peserta.

\section{UCAPAN TERIMA KASIH}

Penulis mengucapkan terima kasih kepada Fakultas Teknik dan Teknologi Informasi Universitas Jenderal Achmad Yani Yogyakarta atas dukungannya dalam bantuan dana pengabdian kepada masyarakat dosen pendanaan internal tahun 2020.

\section{DAFTAR PUSTAKA}

[1] R. Afriansyah and M. S. Pratama, "Implementasi Sistem Ujian Berbasis Komputer Di SMP Negeri 1 Sungailiat," KACANEGARA J. Pengabdi. pada Masy., vol. 3, no. 2, pp. 129-136, Jul. 2020, doi: 10.28989/kacanegara.v3i2.681.

[2] H. Bahar, D. Setiyaningsih, L. Nurmalia, and L. Astriani, "Efektifitas Kahoot Bagi Guru Dalam Pembelajaran Di Sekolah Dasar," KACANEGARA J. Pengabdi. pada Masy., vol. 3, no. 2, pp. 155-162, Jul. 2020, doi: 10.28989/kacanegara.v3i2.677.

[3] U. Yunus, P. Heriyati, A. Lindawati, and M. N. Willyarto, Branding Perguruan Tinggi Di Era Digital. Penerbit Qiara Media, 2019.

[4] A. H. Agus R and B. Ummah, "Strategi Image Branding Universitas Nurul Jadid di Era Revolusi Industri 4.0," Tarbiyatuna J. Pendidik. Islam, vol. 12, no. 1, p. 59, Feb. 2019, doi: 10.36835/tarbiyatuna.v12i1.352.

[5] Permana, R., Tyaswara, B., and Suhadi, M.,"Pemanfaatan Media Sosial Pada MA Nurul Iman Bandung", 2020.

[6] M. Mushlihudin, T. Setiadi, and W. Pujiyono, "Pendampingan Pengelolaan Website Sekolah Muhammadiyah Di Kota Yogyakarta," J. Pemberdaya. Publ. Has. Pengabdi. Kpd. Masy., vol. 2, no. 3, p. 413, Jan. 2019, doi: 10.12928/jp.v2i3.417.

[7] Y. I. Kurniawan, "Pembangunan Website Informasi Sekolah Di Sma Negeri Kerjo, Karanganyar," J-ABDIPAMAS (Jurnal Pengabdi. Kpd. Masyarakat), vol. 2, no. 1, p. 116, Apr. 2018, doi: 10.30734/j-abdipamas.v2i1.169.

[8] A. Priadana, S. Tinggi, M. Informatika, K. Jenderal, and A. Yani, "Sistem Pendukung Keputusan Pemilihan Deleted Domain Dengan Metode AHP Dan SAW," 2018.

[9] R. Ritonga, M. H. Dar, and I. Purnama, "Sistem Informasi Penjualan Pada Toko R2 Collection Di Rantauprapat Berbasis WEB," J. Inform., vol. 7, no. 3, pp. 120-125, Sep. 2019, doi: 10.36987/informatika.v7i3.1382.

[10] S. Arifin and Y. Krisnadita, "Aplikasi Plugin Transfer Domain Di PT Beon Intermedia," Teknol. Inf. Teor. Konsep, dan Implementasi J. Ilm., pp. 1-84, Mar. 2017.

[11] Rachmat, Manajemen Strategik. Bandung: Pustaka Setia, 2014. 